\title{
Barriers of applying Government as a Platform in Practice: Evidence from Germany
}

\author{
Peter Kuhn \\ fortiss \\ pkuhn@fortiss.org
}

\author{
Matthias Buchinger \\ fortiss \\ buchinger@fortiss.org \\ Florian Matthes \\ Technical University of Munich \\ matthes@tum.de
}

\author{
Dian Balta \\ fortiss \\ balta@fortiss.org
}

\begin{abstract}
Government as a Platform (GaaP) is a promising approach to the digital transformation of the public sector. GaaP aims at the development of efficient and user-friendly services by exploiting platform principles such as openness, modularization and cocreation. Hence, GaaP claims to deliver a new level of stakeholder participation in the production of public services. However, the success of GaaP is arguably bound to the context of a country. To address the potential impact of a country's context, the goal of this paper is to identify barriers and measures to overcome them in the application of GaaP in the federal context of Germany. We conduct a literature review and investigate a use case of a German digital government agency by means of documents, expert interviews and workshops. The agency applies GaaP to its architecture management of the federal IT infrastructure. We find five barriers and three measures to overcome. We conclude by discussing implications for theory and practice.
\end{abstract}

\section{Introduction}

Government as a Platform (GaaP) is an approach to the digital transformation of the public sector. The term "GaaP" was coined by Tim O'Reilly [1] and describes the use of platform principles and mechanisms such as openness, modularization and cocreation in order to achieve efficient and user-friendly public services. Often this includes the "platformization" of public sector IT infrastructure [2] and the introduction of middleware (e.g. [3]). By doing so, the approach promises a new level of stakeholder participation in the production of public services [4]. This participation leads to a more efficient and userfriendly public sector, e.g. through innovation.

Scholars have identified benefits of GaaP for both government and its citizens. Those benefits include the chance for citizen participation associated with GaaP [4] and the potential efficiency gains for the public sector [5]. In practice, GaaP is applied by countries like Italy [6] and the UK [7] and is pursued on a supranational level [8].

However, the success of GaaP is arguably bound to the context of a country [9]. For example, in federal countries, the digital infrastructure of governments is often organized in a non-hierarchical way [10]. This makes it more challenging for a government agency to apply the GaaP approach, as decisions and implementations require consensus among the federal states and cannot be decided by a single government agency. Hence, such structures can potentially hinder the effective application of GaaP.

We investigate the case of the German digital government agency FITKO, in order to understand the application of GaaP in the context of the federal IT infrastructure in Germany. The FITKO is a joint agency of the federal government and the German states and was founded in January 2020. Among other tasks, FITKO took over the responsibility for the architecture management of the federal IT infrastructure. The architecture management of the federal IT infrastructure includes the integration of existing infrastructure components, the design of new components and the development of a future to-be architecture [11]. For this architecture management the FITKO pursues a platform approach.

The federal structures of Germany make the work of the FITKO a unique case for studying the application of GaaP in a decentral, non-hierarchical setting. On both the technical and the organizational level, applying GaaP in this setting requires the cooperation of all stakeholders to succeed. The federal structures potentially complicates this cooperation, leading to barriers on the way to GaaP. Hence, we aim at answering the following two research questions: 
RQ1: What are barriers for the application of GaaP in the federal IT architecture management in Germany?

RQ2: What are potential measures for digital government agencies to overcome those barriers?

To address these questions, we conducted a literature review and a case study by means of documents, expert interviews and workshops. The data was collected over a period of one year and findings were frequently shared and discussed with FITKO in order to evaluate them. We find five barriers and three measures to overcome these barriers. Based on our results, we draw conclusions for both, research and practice.

The paper is structured as follows. In chapter 2 the theoretical background on digital platform ecosystems and Government as a Platform is summarized. Then the methodology of the conducted research is explained in chapter 3 , before the description of the case of FITKO. The identified barriers of GaaP are presented in chapter 5 and the developed measures to overcome these barriers are described in chapter 6 . Finally, the concluding chapter gives an outlook on

\section{Background}

\subsection{Digital Platform Ecosystems}

Digital platform ecosystems are an omnipresent phenomenon that is investigated by information systems scholars in numerous publications [12]. Platforms can be described as modular architectures with a core and a periphery [13] on which actors are brought together and get coordinated to innovate and compete [14]. The link between the core and the periphery is facilitated by so-called boundary resources, which play an important role the regulation of the openness of the platform [15, 16, 17]. The modular structure and the boundary resources foster the emergence of ecosystems. Ecosystems can be defined as "set[s] of actors with varying degrees of multilateral, non-generic complementarities that are not fully hierarchically controlled" [18]. An example for such a digital platform ecosystem is the apple app store. It comprises a platform core, the store, on which an ecosystem of apps (periphery) is coordinated by the supply and demand of actors such as developers and iPhone users [16]. Consequently, a digital platform ecosystems "comprises a platform owner that implements governance mechanisms to facilitate value creating mechanisms on a digital platform between the platform owner and an ecosystem of autonomous complementors and consumers" [12].
Digital platforms are closely connected to infrastructure [19]. Digital infrastructures support platforms by "their ability to collect, store, and make digital data available across a number of systems and devices." [19]. While the characteristics and mechanisms of platforms and their ecosystems are broadly studied, the transformation of existing technical infrastructure for platform ecosystems is less so $[20,21]$ and was just recently picked up by research (e.g. [2]). In general, important concepts of the design of platform ecosystems include the definition of roles, price and revenue sharing, the boundary resources and the degree of openness [22]. However, being a platform owner and orchestrating ecosystems is challenging [23, 24]. Among other challenges, it requires solving the chicken egg problem [25]. Existing frameworks for the design and development of platforms are from domains like health care [26] or mobility [24]. Other frameworks in turn consider only specific aspects of platforms like the design of APIs $[27,28]$.

\subsection{Government as a Platform}

Platforms in the public sector are discussed under the term "Government as a Platform" (GaaP), which was coined by Tim O'Reilly [1]. GaaP is used for a broad spectrum of aspects and topics; a uniform definition does not exist [29]. Examples include GaaP as an approach to provide user-friendly public services, GaaP as a means to overcome silo structures and $\mathrm{GaaP}$ as tool box for open platforms and infrastructures [30]. Moreover, platforms in the public sector are considered as a chance for the participation of citizen in the design of administrative processes [4] and for more efficiency [5]. GaaP principles include openness, modularization and co-creation [9].

A central distinction can be made between "Platform for Government" and "Government as Platform" [31]. The former refers to the use of mostly web-based platforms in the public sector. This includes public service portals for online forms and platforms for, e.g., the intermediation of social housing. "Government as a Platform" refers to a more fundamental idea. GaaP is not focusing on transactional platforms like ebay, but rather on platforms as an approach, i.e. something that is based on certain principles and mechanisms [31]. Those principles and mechanisms include the opening of public administration to society and business as well as participation and co-creation of platform content. Based on GaaP, governments can "[do] more with less" [5]. E.g., they do not build new platforms but rather provide infrastructure and thereby enable others 
to build those platforms. This has also been described as leveraging [32].

The benefits associated with GaaP in literature can be structured into benefits for citizens and benefits for the public sector. Benefits of GaaP for citizens mostly revolve around user-friendliness. The integrating capability of technical platforms, for example, simplifies the bundling of services and thereby enables user-friendly service models such as one-stop-shops [3, 33, 34]. In general, many scholars associate platforms with user-centric approaches [33] and innovation [29]. Such approaches can lead to more user-friendly services, e.g. through an enhanced role of the public sector [5]. Benefits of $\mathrm{GaaP}$ for the public sector revolve around efficiency gains. The economies of scale of platform mechanisms [3], for example, results in the saving costs for public sector organizations [5, 34]. More generally, a platform approach allows the public sector to "do more by leveraging more" $[5,32]$, i.e. harnessing "the power of its users to add value - to co-create - its offerings" [1].

GaaP as an approach is applied in practice by countries like Italy [6] and the UK [7] and is pursued on a supranational level [8]. In the UK, the "creation of a middle tier between the front end channels" is the main goal of the GaaP efforts of the "Government Digital Service" [7]. In Italy, the "Agenzia per l'Italia Digitale" (AgID) develops core services and pursues the build-up of competences for digital transformation. With these measures the AgID aims at facilitating an ecosystem of new public services from public and private entities [6]. In both cases, digital government agencies have taken the role of platform owner with major influence on the definition of platform elements and properties.

One aspect that is particularly relevant in the practice of GaaP, is the decentral, federal character of many governments. The dynamic nature of platforms is potentially at odds with the "slow" nature of federal states [10]. First investigations show that these two concepts can be integrated, e.g. in Australia [9], but further research is required.

\section{Methodology}

The problem at hand is the lack of understanding of what determines a successful application of Government as a Platform in a federal context. We attempt to solve that problem by analyzing data from a literature review and a case study. We identify barriers that hinder the successful application and describe measures the FITKO took to overcome them. We seek to ensure the relevance of the research by collecting data from literature in form of a structured literature review and from practice by means of a case study. We seek to ensure the rigor of the research by building on existing knowledge and applying methodologies.

\subsection{Literature review}

For the problem identification and motivation of our research we conducted a literature review. Goal of the review was to achieve a valuable overview regarding the main scientific trends and achievements of the topic GaaP so far. To that end, we followed the guidelines of Webster and Watson [35] as a general structure for the review. In our attempt to be complete and consistent, we searched six databases (DGRL, Scopus, IEEE, ScienceDirect, SpringerLink, and ACM) for relevant scientific literature. To structure the search and the screening of the papers, we follow the systematic review approach described from Petersen et al. [36]. As an application reference, we used the paper from Faber et al. [37].

The search for relevant papers was conducted in two steps. First, we searched the Digital Government Reference Library (DGRL) to get an overview over the literature and narrow down the search queries. Given that the DGRL includes only literature from the government domain, we searched for the terms "platform" as well as "ecosystem" to find all literature related to these topics in the public sector. After eliminating duplicates, the search resulted in 136 papers. Following the approach described by Petersen et al. [36] and Faber et al. [38], we further analyzed these papers in several iterations. Based of that, we classified five as relevant and beneficial for our topic. Second, we extended our search to the five aforementioned databases. Based on the insights from the literature found in the DGRL, we used two more specific queries for our search. The first one was "Government as a Platform" and the second one was ((“Government" OR "E-Government" OR "eGovernment" OR "Public Sector" ) AND ( "Platform" OR "Ecosystem")). We found 487 additional papers in total, of which - after iterative evaluation - we included 14 in our analysis. In summary, 19 papers were analyzed in detail in order to get an understanding of the main topics addressed in scientific literature on GaaP.

\subsection{Case Study}

For the case study, we collected data from documents, expert interviews and workshops on the application of GaaP by FITKO in Germany. Figure 1 gives and overview over the timeline of the case study, Table 1 provides details on the collected data. 
In its role as a digital government agency, the FITKO executes the policies on which the federal and the state's governments agreed upon in the committee "IT Planungsrat". A central responsibility of the FITKO is the coordination of actors on all government levels. This coordination includes strategic development of the technical infrastructure for egovernment in Germany. For this federal IT architecture management the FITKO follows a platform approach, explicitly citing O'Reillys GaaP [1]. Given its coordinating role, FITKO's work dependents on many stakeholders, which include the federal and states governments as well as public and private IT service providers.

Table 1. Description of the collected data

\begin{tabular}{|c|c|c|}
\hline ID & Collected Data & Details \\
\hline IV1 & State expert for infrastructure & $61 \mathrm{~min}$ \\
\hline IV2 & $\begin{array}{l}\text { Federal expert for IT project } \\
\text { management }\end{array}$ & $67 \mathrm{~min}$ \\
\hline IV3 & $\begin{array}{l}\text { Product expert from a IT } \\
\text { service provider }\end{array}$ & $48 \mathrm{~min}$ \\
\hline IV4 & $\begin{array}{l}\text { Product expert from a IT } \\
\text { service provider }\end{array}$ & $59 \mathrm{~min}$ \\
\hline IV5 & $\begin{array}{l}\text { State expert for e- } \\
\text { government decision-making }\end{array}$ & $56 \mathrm{~min}$ \\
\hline IV6 & $\begin{array}{l}\text { Product expert from a IT } \\
\text { service provider }\end{array}$ & $51 \mathrm{~min}$ \\
\hline IV7 & $\begin{array}{l}\text { State expert for IT project } \\
\text { management }\end{array}$ & $47 \mathrm{~min}$ \\
\hline Doc1 & $\begin{array}{l}\text { First sketch of the FITKO } \\
\text { platform approach }\end{array}$ & Presentation \\
\hline Doc2 & $\begin{array}{l}\text { Minutes from the working } \\
\text { groups }\end{array}$ & Documents \\
\hline Doc3 & $\begin{array}{l}\text { Approval of three FITKO } \\
\text { GaaP projects by the IT- } \\
\text { Planungsrat }\end{array}$ & Document \\
\hline Doc4 & $\begin{array}{l}\text { Sketch of the planed } \\
\text { developer platform }\end{array}$ & Document \\
\hline Doc5 & $\begin{array}{l}\text { Internal organization of the } \\
\text { federal IT architecture board }\end{array}$ & Document \\
\hline Doc6 & $\begin{array}{l}\text { Scaling concept of the "FIT- } \\
\text { Connect" routing service }\end{array}$ & Website \\
\hline Doc7 & $\begin{array}{l}\text { Minimal criteria of "EfA"- } \\
\text { Services }\end{array}$ & Document \\
\hline WS1 & $\begin{array}{l}\text { Analysis of existing GaaP } \\
\text { projects with FITKO }\end{array}$ & $\begin{array}{l}3 \mathrm{~h}, \quad 6 \\
\text { participants }\end{array}$ \\
\hline WS2 & $\begin{array}{l}\text { Analysis of federal } \\
\begin{array}{l}\text { infrastructure with IT } \\
\text { architecture board }\end{array}\end{array}$ & $\begin{array}{l}3 \mathrm{~h}, \quad 15 \\
\text { participants }\end{array}$ \\
\hline
\end{tabular}

We studied the application of $\mathrm{GaaP}$ in the federal IT architecture management by FITKO over a period of one year. This included the participation in working groups in the summer of 2020 , which had the purpose of defining the FITKO platform approach, as well as a continuous exchange with the FITKO team. In the course of the year, we had access to internal documents and interviewed experts from stakeholders of the FITKO platform approach. The case study was concluded by two workshops organized by the authors. Both workshops were held online and realized as well as documented by use of an online collaboration tool. One workshop was with FITKO and the other one with the federal IT architecture board. The federal IT architecture board is a committee of the IT-Planungsrat that is made up of state and federal government architecture experts and co-chaired by the FITKO.

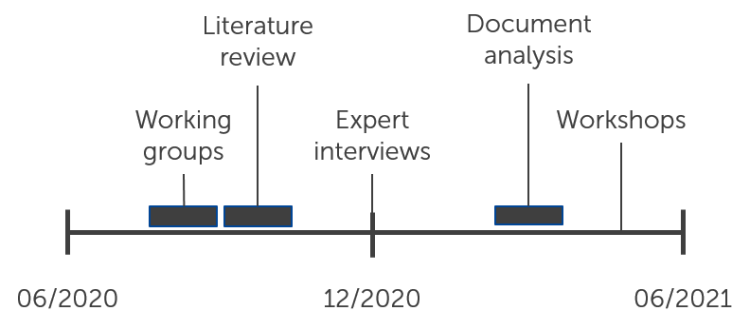

Figure 1. Timeline of the case study

The analyzed documents (abbreviated in the table with "Doc") include working documents, presentations and minutes from boards. The expert interviews (abbreviated "IV") were conducted from November $24^{\text {th }}$ until December $3^{\text {rd }} 2020$ with stakeholders of the FITKO platform approach, i.e., federal and state representatives as well as IT service providers. The interviews took between 47 and 67 minutes, were recorded and transcribed. Before the analysis, the transcriptions were send to the experts for approval. The workshops (abbreviated "WS") took place on May $27^{\text {th }}$ and June $1^{\text {st }} 2021$. The first workshop, with the FITKO team for IT architecture management, analyzed their three major undertakings with respect to platform elements and properties. The second workshop, with the IT architecture board, aimed at specifying a platform approach for the federal IT infrastructure. The collected data was analyzed and insights were frequently shared with FITKO, in order to evaluate and reiterate the results. The three types of data from the case study - documents, interview transcripts and the workshop documentations - were coded regarding barriers and measures. We then merged the coding results and iteratively condensed the final barriers and measure which are presented in the findings. The insights and iterations have constantly been shared and discussed with experts from FITKO. 


\section{The Case of FITKO}

The federal structures of Germany make the work of the FITKO a unique case for studying the application of GaaP in a decentral, non-hierarchical setting. On both the technical and the organizational level, applying GaaP in this setting requires the cooperation of all stakeholders to succeed. The federal structures potentially complicates this cooperation, leading to barriers on the way to GaaP.

In general, the work of FITKO is heavily influenced by the overall efforts of the German public sector to implement the so-called Online Access Act (Onlinezugangsgesetz, short OZG) [39]. The OZG requires all public services to be accessible online by the end of 2022. While FITKO's architecture management is a long-term task, in practice most projects and efforts are aligned to support the shortterm goal of implementing the OZG. Table 2 gives an overview of the activities of FITKO in the context of the case.

\section{Table 2. Overview of the Case}

\begin{tabular}{|c|c|}
\hline \multicolumn{2}{|c|}{ FITKO's federal architecture management } \\
\hline $\begin{array}{l}\text { General } \\
\text { approach }\end{array}$ & Government as a Platform \\
\hline $\begin{array}{ll}\text { Short } & \text { term } \\
\text { goal } & \end{array}$ & $\begin{array}{l}\text { Support the implementation of the } \\
\text { OZG by } 2022\end{array}$ \\
\hline $\begin{array}{l}\text { Major } \\
\text { undertakings }\end{array}$ & $\begin{array}{l}\text { 1. FIT-Connect (approved } \\
\text { 10/2020) } \\
\text { a) Developer portal } \\
\text { b) Routing component } \\
\text { 2. Architecture board (founded } \\
\text { 03/2021) }\end{array}$ \\
\hline
\end{tabular}

FITKO's platform approach was proposed as a strategy for architecture management addressing challenges of the OZG (Doc1). The approach was first described by FITKO in early 2020 by means of a presentation (Doc1). Drawing from Tim O'Reillys "Government as Platform" [1], the role of the government is described as "providing a basis of functions and data based on open standards and components that are available to everyone" (Doc1). The presentation names "high quality support of developers" and easing of "the federal integration challenges" as building block of the approach (Doc1). The general vision is depicted in a visualization of a potential platform and its ecosystem (Doc1).The main benefit FITKO hopes to achieve with its platform approach is efficiency. Already in the first documents, FITKO names fast scaling of online forms and costsaving as a motivation (Doc1). In particular, FITKO stresses the efficiency gains that can be achieved by cooperation, which, in turn, is enabled by the platform approach. The approach "supports the digital transformation of the German public sector by the creation of platform effects and the use of cooperative IT practices" (Doc1). User-friendliness can be considered as an indirect benefit of the FITKO platform approach, given its contribution the implantation of the OZG, which, in turn, is implemented following a service standard to ensure user-friendliness [40].

A major milestone of the FITKO platform approach was the decision of the IT-Planungsrat in Oktober 2020 to greenlight "FIT-Connect". FITConnect is the name of two undertakings with regard to the federal IT infrastructure and its interoperability [41]. The first undertaking is the establishment of an online portal for developers. The portal is supposed to function as a "single point of truth", providing technical information on components and APIs of the federal IT infrastructure. The second undertaking is the development and deployment of a middleware component that can serve as routing service for application data from one state's online portal to another's IT system. In doing so the middleware increases the interoperability of the infrastructure for this use case.

In March 2021 a third decision of the ITPlanungsrat followed, which can be seen as the third major undertaking of the FITKO platform approach. This third undertaking is the creation of a federal IT architecture board made up of architecture experts from the states and federal government [42]. The board is co-chaired by FITKO and supposed to develop the federal IT-architecture by means of architecture principles and standards setting. While the IT architecture board started its work in March 2021, the other two undertaking are about to be launched in the summer of 2021.

\section{Barriers on the road}

Based on our literature review we find that one of the major arguments to introduce $\mathrm{GaaP}$ is the complexity of the public sector $[4,43]$. This complexity creates the need for the orchestration of the involved actors [6] and collective action [1] on order to create public value. In such a setting, hierarchical models are not efficient, but platform-oriented structures can be [4]. At the same time, this complexity might also be what hinders the introduction of GaaP, because the approach requires fundamental changes and, thus, the orchestration and collective action of all actors involved. Starting from this hypothesis we analyzed the described case from Germany, which due to the federal structures - has a particularly complex setting. We identified five barriers the 
FITKO was facing when trying to implement their GaaP approach:

Barrier 1 (B1): difficulty to define what "Government as a Platform" means in practice. There are no detailed guidelines or methods for digital government agencies on how to apply GaaP. Thus, agencies that want to follow the approach need to break down GaaP on their own. This is especially difficult, given there is no common definition of GaaP yet [29] and the fact that the approach is interpreted inconsistently [7]. Furthermore, being an approach rather than a "Platform for Government" [31], GaaP is non-tangible and can be applied to various subjects and on different levels. This lack of definition and nontangibility make breaking down GaaP more difficult and, thus, can be a barrier for the application of GaaP.

In the case of FITKO this barrier is exemplified by the multiple working groups that were instantiated in order to concretize the platform approach. In a presentation from March 2020, the FITKO presents a "sketch of a development and integration platform". However, it took the working groups to break down those basic points into actionable items. The working groups were made up of the states and federal government as well as IT service providers and covered topics from general principles of the approach to technical specifications of a potential platform service for the federal infrastructure (Doc2). This challenge to define a coherent and applicable interpretation of GaaP was also discussed in the WS1, where - after one year of GaaP application - the need for additional workshops that focus specifically on the platform approach was raise by the FITKO. The federal structure made this process particularly challenging given that the involvement of various actors had to be assured. While platform approaches are especially suitable for non-hierarchical structures, these very structures did also hinder its introduction in this case.

Barrier 2 (B2): difficulty to communicate the approach to stakeholders. Since the GaaP approach is a new, mostly unknown concept, it has to be explained to its stakeholders. However, this communication is a challenging task for a digital government agency. For example, the word "platform" is being associated with different concepts including social media and web portals [31]. Communicating the more fundamental meaning of GaaP is more difficult. This is complicated by the non-tangibility of the approach as described above. Thus, the challenge to communicate the approach can be a barrier that hinders the application of GaaP.

In the case of the FITKO, the difficulty to communicate GaaP as an approach was exemplified in many comments during the working groups and workshops. Often individual undertakings were considered as "the" platform the FITKO wants to build and associated with web portals or infrastructure components (Doc2, WS2). For example, in the working groups that were supposed to detail the approach, most of the time had to be used to explain the approach itself. In the WS2, which happened more than one year after the initial proposal of the FITKO, the platform approach was still not understood by all stakeholders (WS2). For example, clarifying "the platform, for what?" was proposed as a next step. Although this barrier is not necessarily exclusive to federal structures, one feature might have added to the challenge. The German states are different in size and, thus, different in their resources. The resulting heterogeneity in know-how and capabilities made communicating the approach more time-consuming because different strategies for different states were necessary.

Barrier 3 (B3): difficulty to define the boundary of the platform. There exist no clear guidelines or methods for the definition of the platform boundaries of GaaP. However, applying a platform approach to "something" requires defining the "something". Digital government agencies that want to apply GaaP have to decide what to include and what not to include into this "something". Such a platform boundary can be hard to define, especially optimizing the balance between openness and control [16]. Not being able to optimize this balance can even lead to platform failure [44]. Another factor is the existing (proprietary) infrastructure which can limit or complicate the boundary definition [24]. Taken together, the challenging optimization of openness and existing limitation can be a barrier in the application of GaaP.

In the case of FITKO, this barrier was exemplified by the challenging design of the routing component (Doc6). On the one hand, the existing infrastructure did not support the targeted use case in full. On the other hand the infrastructure has many components that cover the use case partially or potentially but are not modular and/or open. The challenge for the FITKO was to decide how to include existing components while at the same time maintaining the platform principles. In addition, some stakeholders didn't want the FITKO to be the platform owner of the routing component, making the platform definition even more difficult. For example, interviewee 6 said "I believe, the FITKO can indeed help in coping [with current challenges]. It must concentrate on coordination, however". Based on the - for some unwanted proposed platform boundary many stakeholders exercised active resistance against the GaaP approach in general. The fact that FITKO was operating in a 
historically grown infrastructure did not help: “There are still many proprietary products on the market, which are not opened, which stay closed systems. Probably because they are from private companies“ (interviewee 3). „As the biggest barrier for a strong FITKO I see [company names]. Those are the ones that have the least interest that someone breaks up their platform monopoly" (Interviewee 4). This reluctance hindered the FITKO in defining the "something" and, thus, in applying GaaP. Put differently, federal structures are non-hierarchical while platforms do have a central core with a sole platform owner. The tension between these conceptual differences have contributed to the barrier in this case.

Barrier 4 (B4): difficulty to establish platform thinking. Establishing a platform requires the application of its principles. Thinking based on these principles is challenging because they are contrary to current practices [24]. This includes a lack in culture of openness and federal structures. If platform thinking is not applied, the functioning of platforms cannot be realized. In literature this has been described as "failure of imagination" [44], meaning a focus on features of a product instead of the potential of a platform. Such a lack of imagination can be a barrier for digital government agencies.

In the case of the FITKO, this barrier is exemplified by the distribution of money from federal funds that have been attributed to the digital transformation in light of the COVID-19 pandemic. The distribution is linked to several conditions, regarding legal, organizational and technical aspects (Doc7). However, instead of dedicating the money to build common organizational and technical structures that are in line with the platform principles, the federal government and the states decided that the funds are attributed to the states individually, which then build monopoly services for everyone. The integration of theses services into the general platform approach of the FITKO is yet to be defined. Whether failure of imagination or unwillingness to give up power, the federal structures prevailed in this case and, thus, slowed down the application of GaaP.

Barrier 5 (B5): difficulty of making fundamental changes with limited resources. Many ideas of GaaP require fundamental changes to the way government entities think and work. GaaP is based on a "radical and disruptive embrace of a new economic and organisational model" [7]. In order to make these changes work, the approach has to be communicated and implemented, which requires financial and human resources. Thus, the lack of resources can be a barrier for the application of GaaP.

In the case of the FITKO the GaaP approach comes at a time when little time is left for reaching goals of the OZG. This incentivizes fast results and leaves little space for fundamental changes and new approaches. The FITKO, which is still in the build-up phase, has to contribute to short term goals and establish new structures at the same time. Or, as one interviewee (interviewee 6) put it: "To effectively navigate under these circumstances and ensuring stability despite what's already going, is a mad challenge". Not having the appropriate resources can, thus, hinder the application of GaaP. The federal aspect here is that the reluctance to work together in the past created the urgency of the OZG in the first place. In this sense the federal structures also contributed to the limitation of resources in 2021 .

Taken together, we find several barriers that explain the difficulties to apply GaaP in Germany. Moreover, federalism is at least interacting with the presented barriers if not contributing to them. Addressing the barriers with general knowledge on federalism in mind could, thus, help to solve real world problems in the digital transformation of the public sector and at the same time help to evaluate the conceptualization of GaaP made in literature.

\section{Measures to overcome}

Based on the barriers described in the previous chapter, the FITKO applied three measures that helped to overcome these barriers.

Measure 1 (M1): break down GaaP into tangibles. GaaP as applied by the FITKO is not a platform for government but rather an approach to architecture management and, thus, not tangible. This non-tangibility can make the application of GaaP challenging. One measure to overcome this, is the translation of the approach into concrete undertakings and projects. Those undertakings and projects are potentially more tangible than the general approach and are, thus, better to communicate and implement. Therefore, this measure can arguably help overcoming $\mathrm{B} 1$ and $\mathrm{B} 2$.

In the case of FITKO, three undertakings were proposed to the IT-Planungsrat that are tangible and at the same time substantiate the general GaaP approach. The routing component is tangible in the sense that it is a technical component that can be used for a specific use case by states. At the same time, the component can be seen as a boundary resource that connects the IT "worlds" [16] of the states. The developer platform will be a web portal and, thus, visible. Also, successful examples of such platforms, e.g. from google help communicating the undertaking. Finally, the board is tangible in the sense that decision of the board will be documented and accessible. The tangibility helped 
reaching a consensus and getting the undertakings approved by the IT-Planungsrat.

Measure 2 (M2): get a clear mandate. At the beginning, the GaaP approach of the FITKO was just a proposal. However, given its fundamental nature, the approach required fundamental changes, which need an assertiveness to be enforced. One measure to overcome this barrier is getting a clear mandate by all stakeholders to implement these fundamental changes. This mandate should also include the appropriate funds to make those changes. Based on this mandate, changes are to be expected, funded and harder to resist. Therefore, this measure can arguably help overcoming $\mathrm{B} 3, \mathrm{~B} 4$, and B5.

In the case of the FITKO, the decision of the ITPlanungsrat to approve the three undertaking proposed and implemented by FITKO, gave the agency a clear mandate to "own" central activities towards a platform approach (Doc3). In particular, the decisions give the FIKTO the mandate to develop and operate a new middleware that serves as a platform on which state IT systems can exchange application data. Also, the design and operation of a developer platform is assigned to FITKO, giving the agency strong influence on the openness and accessibility of information on architecture components and interfaces. In the case of the IT architecture board, FITKO functions as co-chair and, thus, takes a central role comparable to the one of a platform owner. Taken together the clear mandate for FITKO to take a central role in all three major undertakings enables the agency to push their platform approach.

Measure 3 (M3): don't call it platform. Despite its various aspects and dimensions GaaP is based on simple principles such as openness and co-creation. Incorporating these principles in basic decisions can already help moving forward, even if GaaP as an approach is not yet established, understood or accepted. This also avoids the problem that the term "platform" has various connotations and meanings, which can complicate its application. Following basic GaaP principles without contextualizing them within the bigger approach might, thus, simplify the work of digital government agencies. Therefore, this measure can arguably help overcoming the B2 and B3.

In the case of the FTIKO, this can be exemplified by the API of a new middleware component for routing application data. This API was specified by FITKO using the OpenAPI standard. In the spirit of openness, the specification was published at an early stage, leading to multiple suggestions for improvement. In fact, the current version includes endto-end encryption, which was significantly contributed to from civil society. Another example for simple steps making a difference are the two workshops (WS1 and
WS2). In both workshops basic platform concepts were applied to different subjects of the work of FITKO and the IT architecture board. Discussions, for example, on what could be seen as the platform core, its boundary and the ecosystem of the federal IT infrastructure helped the members of the board to clarify the platform approach and lead to insights on potential improvements of the components and their interfaces in the spirit of the approach. Finally, in the approved documents describing FITKO's undertakings the platform approach is not even mentioned and the word platform is used only in the context of one of the undertakings, referring to infrastructure (Doc3). Taken together, many activities of the FITKO followed a platform approach and platform principle without explicitly calling it a platform. From our exchange with FITKO it was apparent that this was not a conscious decision. However, it helped overcoming B2, B3, B4, and B5.

\section{Conclusions and outlook}

$\mathrm{GaaP}$ is an approach to the digital transformation in the public sector. The approach can yield benefits for both the government and its citizens, especially user-friendly public services and efficiency. Unfortunately, GaaP has a varying success track record in different contexts. We investigate the case of FITKO in order to understand the application of GaaP in a federal context. Based on a literature review, we conduct a case study by means of document analysis, expert interviews and workshops. We identify five barriers that hindered the application of GaaP in Germany and describe three measures the FITKO used to overcome them.

Before drawing conclusions, we need to highlight two major limitations of the paper. Our paper concentrates on a single case study, which limits its general applicability. As discussed in the previous chapter, the finding could be specific for federal countries or for particular features of the digital transformation in Germany. Consequently, other countries can experience different barriers or none of the barriers at all. Also, the measures might not work in different contexts. Second, while we were in constant exchange with the FITKO and tried to investigate as much data as possible, we still could not incorporate all details and dimension of the FITKO platform approach. The barriers and measure, thus, might be incomplete.

Based on the described limitations two questions can be raised in order to draw conclusions. The first question is, whether those findings are specific to the federal context of Germany. Federal structures require consensus and coordination of various actors [10]. 
Arguably, this need for consensus can account for Barriers 2 and 3, because the communication of the approach and the definition of the platform boundary are more time-consuming and complex with more actors. Following this premise, countries without federal structures should not encounter those barriers. However, a single case study cannot answer this question. Yet, we provide evidence that those barriers can occur in a certain context. The second question is, whether our findings are specific to the public sector. Literature shows that in the private sector, too, companies struggle with the establishment of platforms $[24,44]$. On the one hand, private sector companies often build a tangible platform instead of applying a general approach to a whole sector. On the other hand, those platforms are based on the same principles as GaaP. Barriers such as Barrier 4, the establishment of platform thinking, apply there, as well. While single case study cannot answer this question, our results provide evidence that the structures of a public sector can complicate the application of GaaP in practice.

Conditional on the limitations and based on the discussed questions, we draw the following conclusions. First, our case study shows that GaaP can be challenging in practice. While it promises benefits, it also requires a fundamental transformation that is not trivial. Governments that consider applying GaaP should consider their context and capabilities to handle this transformation and follow examples from successful countries. Scholars could extend their investigation of countries that applied GaaP successfully to understand the factors and contexts that helped and identify steps that other countries can copy. Second, while conceptualization of GaaP exist, the variety and different levels of GaaP is quite broad. Governments should consider what part of GaaP they actually need and want. Literature should classify different GaaP approaches and use cases in order to better understand all its aspects and complexities. This could also mean to better differentiate GaaP general IS literature on platforms and platform ecosystems.

While limitations exist, we believe that our research is valuable to both theory and practice. In particular, we hope that the presented insights support the application of GaaP in practice and increases userfriendliness and efficiency in the public sector.

\section{References}

[1] O'Reilly, T., “Government as a Platform”, Innovations: Technology, Governance, Globalization 6(1), 2011, pp. 1340.

[2] Bygstad, B., and O. Hanseth, "Transforming Digital Infrastructures through platformization”, ECIS, (2018).
[3] González, L., R. Ruggia, J. Abin, et al., "A ServiceOriented Integration Platform to Support a Joined-Up EGovernment Approach: The Uruguayan Experience", Advancing Democracy, Government and Governance, Springer (2012), 140-154.

[4] Al-Ani, A., "Government as a Platform: Services, Participation and Policies", In M. Friedrichsen and Y. Kamalipour, eds., Digital Transformation in Journalism and News Media: Media Management, Media Convergence and Globalization. Springer International Publishing, Cham, 2017, 179-196.

[5] Janssen, M., and E. Estevez, "Lean government and platform-based governance-Doing more with less", Government Information Quarterly 30, 2013, pp. S1-S8.

[6] Cordella, A., and A. Paletti, "Government as a platform, orchestration, and public value creation: The Italian case", Government Information Quarterly 36(4), 2019, pp. 101409. [7] Brown, A., J. Fishenden, M. Thompson, and W. Venters, "Appraising the impact and role of platform models and Government as a Platform (GaaP) in UK Government public service reform: Towards a Platform Assessment Framework (PAF)", Government Information Quarterly 34(2), 2017, pp. 167-182.

[8] European Commission, Digital Platform for Public Services, DG Joint Research Centre, 2018.

[9] Gil-Garcia, J.R., P. Henman, and M.A. Avila-Maravilla, "Towards 'Government as a Platform'? Preliminary Lessons from Australia, the United Kingdom and the United States", Proceedings of Ongoing Research, Practitioners, Posters, Workshops, and Projects of the International Conference EGOV-CeDEM-ePart 2019, (2019).

[10] Scholta, H., M. Niemann, S. Halsbenning, M. Räckers, and J. Becker, "Fast and Federal - Policies for NextGeneration Federalism in Germany", 52nd Hawaii International Conference on System Sciences, HICSS 2019, Grand Wailea, Maui, Hawaii, USA, January 8-11, 2019, (2019), 1-10.

[11] FITKO, "Föderales IT-Architekturmanagement", 2020. https://www.fitko.de/dynasite.cfm?friendly_path_info=/itarchitektur\&

[12] Hein, A., M. Schreieck, T. Riasanow, et al., "Digital platform ecosystems", Electronic Markets 30(1), 2020, pp. 87-98.

[13] Baldwin, C.Y., and C.J. Woodard, "The Architecture of Platforms: A Unified View", SSRN Electronic Journal, 2008.

[14] Gawer, A., "Bridging differing perspectives on technological platforms: Toward an integrative framework", Research Policy 43(7), 2014, pp. 1239-1249.

[15] Boudreau, K., "Open Platform Strategies and Innovation: Granting Access vs. Devolving Control", Management Science 56(10), 2010, pp. 1849-1872.

[16] Ghazawneh, A., and O. Henfridsson, "Balancing platform control and external contribution in third-party development: the boundary resources model", Information Systems Journal 23(2), 2013, pp. 173-192.

[17] Karhu, K., R. Gustafsson, and K. Lyytinen, "Exploiting and Defending Open Digital Platforms with Boundary Resources: Android's Five Platform Forks", Information Systems Research 29(2), 2018, pp. 479-497. 
[18] Jacobides, M.G., C. Cennamo, and A. Gawer, "Towards a theory of ecosystems", Strategic Management Journal 39(8), 2018, pp. 2255-2276.

[19] Constantinides, P., O. Henfridsson, and G.G. Parker, "Introduction-Platforms and Infrastructures in the Digital Age”, Information Systems Research 29(2), 2018, pp. 381400 .

[20] Leijon, E., J. Svenheden, and F. Svahn, "Platform Thinking in Incumbent Firms: From Concept to Capability", HICSS Proceedings, (2017).

[21] de Reuver, M., C. Sørensen, and R.C. Basole, "The Digital Platform: A Research Agenda", Journal of Information Technology 33(2), 2018, pp. 124-135.

[22] Schreieck, M., M. Wiesche, and H. Krcmar, "Design and Governance of Platform Ecosystems - Key Concepts and Issues for Future Research", ECIS, (2016).

[23] Ivarsson, F., and F. Svahn, "Becoming a Digital Ecosystem Orchestrator - The Sydved Case", ECIS Proceedings, (2020).

[24] Weiss, N., M. Wiesche, M. Schreieck, and H. Krcmar, "Learning to be a Platform Owner: How BMW Enhances App Development for Cars", IEEE Transactions on Engineering Management, 2020, pp. 1-17.

[25] Trabucchi, D., "Let's Get a Two-Sided Platform Started: Tactics to Solve the Chicken and Egg Paradox", Journal of Business Ecosystems (JBE) 1(1), 2020, pp. 6377.

[26] Herman, H., S.S. Grobbelaar, and C. Pistorius, "The design and development of technology platforms in a developing country healthcare context from an ecosystem perspective", BMC Medical Informatics and Decision Making 20(1), 2020, pp. 55.

[27] Basole, R.C., "On the Evolution of Service Ecosystems: A Study of the Emerging API Economy”, In P.P. Maglio, C.A. Kieliszewski, J.C. Spohrer, K. Lyons, L. Patrício and Y. Sawatani, eds., Handbook of Service Science, Volume II. Springer International Publishing, Cham, 2019, 479-495.

[28] Bondel, G., D.H. Bui, A. Faber, D. Seidel, and M. Hauder, "Towards a Process and Tool Support for Collaborative API Proposal Management", AMCIS 2019 Proceedings, 2019.

[29] Seo, H., and S. Myeong, "The Priority of Factors of Building Government as a Platform with Analytic Hierarchy Process Analysis", Sustainability 12(14), 2020, pp. 5615.

[30] Pope, R., "A working definition of Government as a Platform", Medium, 2019. https://medium.com/digitalhks/aworking-definition-of-government-as-a-platform-

1fa6ff2f8e8d

[31] Thompson, M., "Government as a platform, or a platform for government? Which are we getting?", ComputerWeekly.com,

2015.

https://www.computerweekly.com/opinion/Government-asa-platform-or-a-platform-for-government-Which-are-we-

getting

[32] Millard, J., "Open governance systems: Doing more with more", Government Information Quarterly 35(4, Supplement), 2018, pp. S77-S87.

[33] Pappa, D., and C. Makropoulos, "Designing a Brokerage Platform for the Delivery of E-government Services to the Public", Knowledge Management in Electronic Government, Springer (2004), 178-189.
[34] Yoshimoto, A., S. Muto, G. Kaneda, et al., "Local Government ICT Platform Standardization Activities of ICT Systems and Services for Offering High Value-added Service by Interacting Local Governments, Regional Institutions and Private Sector", Towards Sustainable Society on Ubiquitous Networks, Springer US (2008), 315326.

[35] Webster, J., and R.T. Watson, "Analyzing the Past to Prepare for the Future: Writing a Literature Review", MIS Quarterly 26(2), 2002, pp. xiii-xxiii.

[36] Petersen, K., R. Feldt, S. Mujtaba, and M. Mattsson, "Systematic Mapping Studies in Software Engineering", (2008).

[37] Faber, A., F. Matthes, and F. Michel, Digital Mobility Platforms and Ecosystems, Technischen Universität München, 2016.

[38] Faber, A., M. Riemhofer, S.-V. Rehm, and G. Bondel, "A Systematic Mapping Study on Business Ecosystem Types", AMCIS 2019 Proceedings, 2019.

[39] Bundesministerium der Justiz und für Verbraucherschutz, "OZG - Gesetz zur Verbesserung des Onlinezugangs zu Verwaltungsleistungen”, Gesetze-imInternet.de, 2017. https://www.gesetze-iminternet.de/ozg/BJNR313800017.html

[40] Bundesministerium des Innern, für Bau und Heimat, "Servicestandard für die OZG-Umsetzung", onlinezugangsgesetz.de, 2020. http://www.onlinezugangsgesetz.de/Webs/OZG/DE/umsetz ung/servicestandard/servicestandard-

node.html;jsessionid=D7965FFC6E841FC331751EC0E18 4DE2F.2_cid287

[41] IT-Planungsrat, "IT-Planungsrat - 33. Sitzung des ITPlanungsrats vom 23. Oktober 2020", Webseite des ITPlanungsrats, 2020.2 https://www.itplanungsrat.de/SharedDocs/Sitzungen/DE/2020/Sitzung_33 .html?pos $=5$

[42] IT-Planungsrat, "IT-Planungsrat - Aktuelle Meldungen - Neues Gremium des IT-Planungsrats: das föderale ITArchitekturboard", Webseite des IT-Planungsrats. https://www.it-

planungsrat.de/SharedDocs/Startseitenmeldungen/DE/Start seite_IT_Architekturboard.html

[43] Rantanen, M.M., J. Koskinen, and S. Hyrynsalmi, "EGovernment Ecosystem: A new view to explain complex phenomenon", 2019 42nd International Convention on Information and Communication Technology, Electronics and Microelectronics (MIPRO), (2019), 1408-1413.

[44] Alstyne, M.W.V., G.G. Parker, and S.P. Choudary, "6 Reasons Platforms Fail", Harvard Business Review, 2016. https://hbr.org/2016/03/6-reasons-platforms-fail 